\title{
FRAMEWORK DE MAPEAMENTO DOS FACILITADORES DA GESTÃO DO CONHECIMENTO APLICADO AO DESENVOLVIMENTO DE SERVIÇOS EMPRESARIAIS INTENSIVOS EM CONHECIMENTO
}

\section{FRAMEWORK FOR MAPPING THE KNOWLEDGE MANAGEMENT ENABLERS APPLIED TO THE KNOWLEDGE INTENSIVE BUSINESS SERVICES DEVELOPMENT}

\author{
Abraão Freires Saraiva Júnior ${ }^{1}$; Reinaldo Pacheco da Costa ${ }^{2}$ \\ ${ }^{1}$ Escola Politécnica da Universidade de São Paulo- POLI USP - São Paulo - Brasil \\ abraaofsjr@gmail.com \\ ${ }^{2}$ Escola Politécnica da Universidade de São Paulo- POLI USP - São Paulo - Brasil \\ rpcosta@usp.br
}

\begin{abstract}
Resumo
Nas economias modernas, é crescente a participação do setor de serviços em relação à geração de emprego e à criação de valor. Uma parte deste setor, denominado KIBS (Knowledge-Intensive Business Services - Serviços Empresariais Intensivos em Conhecimento), diz respeito às empresas em que o conhecimento é a principal fonte de recursos e de vantagem competitiva. Neste contexto, este artigo objetiva propor um framework de mapeamento dos facilitadores da gestão do conhecimento a ser aplicado no desenvolvimento de produtos de uma empresa prestadora de serviços intensivos em conhecimento, como no caso de consultorias empresariais. Em um estudo de caso, o framework proposto é aplicado em uma firma prestadora de serviços de consultoria empresarial brasileira. Conclui-se que o framework proposto pode auxiliar gestores a diagnosticarem as instâncias em que o processo de criação e gestão do conhecimento necessitam ser melhoradas ou estão fortalecidas no tocante ao desenvolvimento de serviços intensivos em conhecimento.
\end{abstract}

Palavras-chave: Serviços Empresariais Intensivos em Conhecimento; Facilitadore da Gestão do Conhecimento; Processo de Criação do Conhecimento.

\section{Introdução}

Os últimos anos vem acompanhados de transformações constantes em todos os setores da economia. A abertura de mercado e o rápido desenvolvimento de novas tecnologias têm impactado de maneira incisiva as organizações. Ao estudar as transformações do mundo através da história, Drucker (1993) lançou as bases do que considera a nova ordem que iria sobrepor à era capitalista. De acordo com a sua visão, a Sociedade do Conhecimento, em que o principal recurso é o 
conhecimento, é portador de efeitos substanciais sobre as economias e as organizações, com destaque às empresariais. Aliadas a este contexto, a importância do conhecimento e da inovação na economia moderna, além do acentuado crescimento do setor de serviços vivenciado a partir da segunda metade do século XX (KUBOTA, 2006), podem ser justificativas para o aumento do interesse de pesquisadores em estudar empresas fornecedoras de serviços empresariais intensivos em conhecimento (KIBS - Knowledge-Intensive Business Services - cognominado como "as KIBS”, na acepção de empresas), principalmente a partir da década de 90 (MULLER; DOLOREUX, 2007).

As KIBS exercem um papel de facilitadores do processo de inovação na economia, inclusive em outros setores diferentes do de serviços. Assim como os serviços de informação e comunicação, as KIBS contribuem para o incremento da produtividade das economias (ANTONELLI, 1998). De acordo com Miles et al. (1995), as KIBS envolvem atividades econômicas que se destinam a resultar na criação, acumulação e disseminação do conhecimento para outras organizações. Dentre as KIBS, podem-se destacar as empresas prestadoras de serviços de consultoria empresarial em que a preocupação com a gestão do conhecimento emerge como um dos discursos freqüentes dos gestores (NAKANO, 2002) e estudiosos deste tipo de empresa.

Em anos recentes, pesquisas intensificaram esforços para aprofundar a compreensão de como as organizações trabalham com o conhecimento para desenvolver novos produtos, novos processos e novas formas ou arranjos organizacionais mais flexíveis de forma a conseguir gerar uma vantagem competitiva sustentável (SILVA, 2004). Pode-se entender como "trabalhar com o conhecimento" o processo de criação, identificação, coleta, adaptação, organização, aplicação e compartilhamento do conhecimento na organização (ANDERSON; APQC, 1996). Tanto em termos de linha de pesquisa acadêmica, como também no âmbito empresarial, esses sete processos estão sob a égide do campo denominado de Gestão do Conhecimento (GC). Autores são partidários da idéia de que, para a empresa, a implantação coordenada da GC pode ser geradora de vantagem competitiva sustentável por ser de difícil imitação, pois está enraizada nas pessoas que trabalham na empresa e não em recursos físicos que são facilmente imitáveis pelos concorrentes (QUINN et al., 1997) e que são menos flexíveis para reagir às incertezas do ambiente (THOMKE; REINERTSEN, 1998).

Para o caso específico do processo de desenvolvimento de produtos (PDP), muitas empresas reconhecem a importância da GC, tal como argumentam Silva e Rozenfeld (2003). Das várias abordagens teóricas relacionadas à $\mathrm{GC}$, a que possui mais proximidade ou adequação com a necessidade de se entender a GC no PDP é a teoria apresentada na escola da criação do conhecimento de Nonaka e Takeuchi (1995), em particular o modelo SECI. Isso porque, em termos conceituais, o PDP é um processo que possuem características essencialmente de criação e 
disseminação de novos conhecimentos, características estas que também são focalizadas por Nonaka e Takeushi (1995) no modelo SECI (SILVA; ROZENFELD, 2003).

Independentemente de a gestão do conhecimento ser aproveitada de forma parcial (setor ou processo - ex: PDP) ou total (empresa como um todo), se uma organização almeja evitar o desenvolvimento aleatório e não-sistemático do seu conhecimento interno, esta deve buscar mecanismos que facilitem o desenvolvimento consistente e ordenado do conhecimento (ICHIJO et al., 1998). Esses mecanismos que dão suporte à GC na organização são tratados na literatura internacional como Knowledge Managment Enablers (transcritos como Facilitadores ou Viabilizadores da Gestão do Conhecimento para efeito do corrente estudo). Os facilitadores da GC se constituem em mecanismos que quebram barreiras ao desenvolvimento de conhecimento, estimulando os membros da organização a criarem e compartilharem conhecimentos e experiências adquiridos em prol da evolução da organização em que atuam (ICHIJO et al., 1998; LEE, et al., 2008).

Buscando uma integração entre a literatura sobre KIBS, GC, PDP e facilitadores da GC, o corrente artigo objetiva propor um framework de mapeamento dos facilitadores da gestão do conhecimento a ser aplicado no desenvolvimento de produtos de uma empresa prestadora de serviços intensivos em conhecimento, como no caso de consultorias empresariais, a partir da ótica do modelo de criação de conhecimento organizacional proposto por Nonaka e Takeuchi (1995).

Considera-se duas justificativas para a realização deste trabalho. A primeira vai ao encontro da justificativa apresentada por Silva e Rozenfeld (2003), residindo no fato de que o relacionamento entre PDP e GC, embora percebido e comentado na literatura, vem sendo tratado de forma fragmentada e pouco sistemática, o que limita a compreensão de como os gestores avaliam este relacionamento e, consequentemente, como podem melhorar esta relação nas empresas em que atuam. Este problema é intensificado quando o objeto de estudo trata-se de empresas prestadores de serviços, em especial às intensivas em conhecimento. A segunda justificativa reside na não existência de um framework que integre o processo de criação de conhecimento, como o modelo SECI de Nonaka e Takeuchi (1995), com os facilitadores da GC no contexto de organizações que prestam serviços intensivos em conhecimento, como no caso das consultorias empresariais. Desta forma, ao se propor um framework que avalia a situação da GC no PDP a partir da geração de resultados na forma de um "mapa" detalhado, almeja-se subsidiar decisões gerenciais no tocante à criação e melhoria de mecanismos e ações que favorecem o desenvolvimento de conhecimento na empresa.

Além desta introdução, o artigo é estruturado a partir da fundamentação teórica, em que são discutidos conceitos e aspectos relacionados com as KIBS, com o processo de criação do conhecimento enfatizando o modelo SECI e com os facilitadores da GC. Na seção posterior, são 
enfatizados os procedimentos metodológicos que estruturam o estudo. Em seguida, é realizada a proposição de um framework de mapeamento da GC no PDP que integra os facilitadores da GC. Na seqüência, é apresentada e discutida uma aplicação do framework proposto a partir de informações coletadas em uma empresa de consultoria empresarial, bem como os resultados alcançados. Na última seção, são expostas as considerações finais dos autores, as limitações da pesquisa e as recomendações para trabalhos futuros.

\section{Fundamentação Teórica}

Para uma melhor compreensão do estudo realizado e do framework de mapeamento proposto, são apresentados e discutidos conceitos e aspectos relacionados com as KIBS, com ênfase em empresas prestadoras de serviços de consultoria empresarial, com o modelo SECI de criação de conhecimento de Nonaka e Takeuchi (1995) e com os facilitadores/viabilizadors da GC.

\subsection{Serviços Empresariais Intensivos em Conhecimento - KIBS}

Em um trabalho seminal de 1995, Ian Miles juntamente com outros pesquisadores da Universidade de Manchester lançou os primeiros estudos sistematizados acerca de KIBS. Os Serviços Empresariais Intensivos em Conhecimento, tradução provinda do inglês de KnowledgeIntensive Business Services, são definidos como empresas que vendem serviços para outras empresas tendo o conhecimento e a informação como os principais componentes dos serviços. Esse tipo de empresa "envolvem atividades econômicas que se destinam a resultar na criação, acumulação e disseminação do conhecimento" e está em constante contato com os usuários dos serviços (MILES et al., 1995, p. 18).

Muller (2001, p.2) descreve KIBS como "firmas que excutam, principalmente para outras firmas, serviços cercados de alto valor agregado intelectual". Miles (1995) identifica duas categorias principais de KIBS que se diferenciam entre si pelo uso mais intensivo de tecnologias da informação e comunicação (TIC). O Quadro 1 apresenta os dois tipos de KIBS conforme taxonomia de Miles et al. (1995):

\begin{tabular}{|c|c|c|}
\hline \multicolumn{2}{|c|}{ Quadro 1 - Tipos de KIBS } & \multirow{2}{*}{ NIB̃o-KIBS I } \\
\hline $\begin{array}{c}\text { Serviços profissionais tradicionais, passíveis de } \\
\text { serem utilizadores intensos de novas tecnologias }\end{array}$ & $\begin{array}{c}\text { Baseados em novas } \\
\text { tecnologias }\end{array}$ & Saúde \\
\hline Marketing e propaganda & Software & Correios \\
\hline Treinamento & Treinamento em novas & Administração pública \\
\hline Consultoria em gestão & Telecomunicações & Reparo/manutenção \\
\hline Contabilidade & Engenharia técnica & Lazer/turismo/entretenimento \\
\hline Serviços financeiros, legais e ambientais & Laboratórios & \\
\hline
\end{tabular}

Fonte: Adaptado de Miles et al. (1995) 
Na literatura, é discutida a importância das KIBS para a economia, principalmente, no tocante à inovação. Hauknes (1998) identifica três papéis a serem desempenhados pelas KIBS: facilitadores, portadores e fontes de inovação. Enquanto facilitadores da inovação, as KIBS ajudam diretamente seus clientes (empresas) na geração de inovação. O autor cita como exemplo, o caso de um consultor de gestão que auxilia um de seus clientes a desenvolver e implantar novos sistemas de contabilidade ou o auxilia a desenvolver um novo canal de distribuição para seus produtos. Como portadores de inovação, as KIBS participam na transferência de inovações existentes de uma empresa para outra e tem como exemplo as empresas que desenvolvem treinamento dos consumidores finais em softwares e programas utilizados por outras empresas. E, por fim, as KIBS atuam com fontes de inovação na medida em que desenvolvem inovações a partir de interações com outras empresas que são seus clientes. Como exemplos, podem ser destacadas as empresas de publicidade que desenvolvem e executam campanhas novas para seus clientes e estão em constante interação com estes na implementação de mudanças na campanha.

Vale ressaltar que firmas baseadas em conhecimento, tais como as KIBS, possuem serviços fortemente customizados às necessidades dos clientes. Essas firmas são caracterizadas pela não padronização, criatividade, alta dependência dos indivíduos e resolução de problemas não triviais. São empresas cujos principais recursos são as pessoas (DUHAN et al., 2001). Entre estas empresas, podemos destacar as prestadoras de serviços de consultoria empresarial que são empresas com alto nível de conhecimento tácito e explícito, com equipe de trabalho engajada na geração e comunicação da informação para satisfazer a necessidade (resolver problema) específica do cliente. Desta forma, tal como afirma Nakano (2002), neste tipo de empresa, a preocupação com o conhecimento emerge como um dos discursos freqüentes dos gestores. Outra característica das empresas de consultorias, conforme aponta Jesus (2005), é que as informações e conhecimentos oriundos de seus processos internos são combinados com conhecimentos e informações de seus clientes, de universidades e laboratórios e de outros agentes que tenham contato, o que confere um caráter dinâmico e externamente condicionado do conhecimento da empresa.

\subsection{O Modelo de Criação do Conhecimento de Nonaka e Takeuchi (1995)}

Nos anos 80, o tema "conhecimento" tornou-se mais presente devido ao advento das abordagens teóricas relacionadas à sociedade do conhecimento, ao aprendizado organizacional e às competências essenciais na gestão estratégica (SPENDER, 1996). Em anos recentes, as pesquisas nestas abordagens intensificaram suas aplicações práticas e o aprofundamento teórico, focalizando a necessidade de se entender como as organizações trabalham com o conhecimento para desenvolver 
novos produtos, novos processos e novas formas ou arranjos organizacionais mais flexíveis, proporcionando uma vantagem competitiva sustentável (SILVA; ROZENFELD, 2003). Para Davenport e Prusak (2000), as únicas vantagens competitivas que uma empresa possui estão associadas ao que ela coletivamente sabe, à eficiência com que usa o que sabe, e à presteza com que adquire e utiliza novos conhecimentos.

Quando as organizações inovam, elas não só processam informações, de fora para dentro, com o intuito de resolver os problemas existentes e se adaptar ao ambiente em transformação. As organizações criam também novos conhecimentos e informações, de dentro para fora, a fim de redefinir tanto os problemas quanto as soluções e, nesse processo, recriar seu meio (NONAKA; TAKEUCHI, 1995). Alguns autores convergem para a idéia de que o conhecimento é formado por informação que pode ser expressa, verbalizada, e é relativamente estável ou estática, em completo relacionamento com uma característica mais subjetiva e não palpável, que está na mente das pessoas e é relativamente instável ou dinâmica, envolvendo experiência, contexto, interpretação e reflexão (POLANYI, 1966; NONAKA; TAKEUCHI, 1995). Essas duas partes constituintes do conhecimento são tratadas por pesquisadores, entre eles Nonaka e Takeuchi (1995), como dois formatos de conhecimentos intrinsecamente relacionados e com epistemologia própria, a saber:

- Tácito: conhecimento subjetivo; habilidades inerentes a uma pessoa; sistema de idéias, percepção e experiência; difícil de ser formalizado, transferido ou explicado a outra pessoa;

- Explícito: conhecimento relativamente fácil de codificar, transferir e reutilizar; formalizado em textos, gráficos, tabelas, figuras, desenhos, esquemas, diagramas, etc.; facilmente organizados em bases de dados e em publicações em geral.

Nonaka e Takeuchi (1995) argumentam que o segredo para a criação do conhecimento está na mobilização e conversão do conhecimento tácito em explícito e vice-versa. Como esta teoria também se preocupa com a criação do conhecimento organizacional, em oposição à criação do conhecimento individual, ela possui sua própria ontologia que lida com os níveis de entidades criadoras de conhecimento (individual, grupal, organizacional e interorganizacional/ambiente). No tocante à direção ontológica, o conhecimento nasce em um nível individual, sendo ampliado pela dinâmica da interação para um nível organizacional e, posteriormente, para um nível interorganizacional. A geração de conhecimento ocorre quando a interação do conhecimento tácito e do conhecimento explícito eleva-se dinamicamente de um nível ontológico inferior até níveis mais altos. Vale ressaltar que, nessa dimensão ontológica, conhecimento só é criado por indivíduos, ou seja, uma organização ou uma rede interorganizacional não podem criar conhecimento sem indivíduos. Os grupos funcionam como sintetizadores do conhecimento e a organização como amplificadores do conhecimento (NONAKA; TAKEUCHI, 1995).

$\mathrm{Na}$ literatura de organização do trabalho e na prática empresarial, argumenta-se que a 
formação de equipes auto-organizadas proporciona um contexto compartilhado no qual os indivíduos podem interagir uns com os outros. Desta forma, os indivíduos podem desenvolver um diálogo que pode envolver considerável conflito e discordância. Essa contradição leva os indivíduos a questionarem as premissas existentes e buscarem novos sentidos em suas experiências. Esse tipo de interação dinâmica no nível do grupo facilita a transformação do conhecimento pessoal em conhecimento organizacional (NONAKA; TAKEUCHI, 1995).

Nonaka e Takeuchi (1995) advogam que a criação do conhecimento é iniciada com a socialização e transcorre em quatro modos de conhecimento, formando uma espiral. A amplificação do conhecimento dá-se pela passagem deste por quatro modos de conversão, descritos no Quadro 2:

Quadro 2 - Os quatro modos de conversão do conhecimento

\begin{tabular}{|c|c|c|c|}
\hline $\begin{array}{c}\text { MODO DE } \\
\text { CONVERSÃO } \\
\end{array}$ & DESCRIÇÃO & $\begin{array}{c}\text { DIREÇ̃̃O } \\
\text { ONTOLÓGICA } \\
\end{array}$ & EXEMPLOS DE AÇÕES \\
\hline Socialização & $\begin{array}{l}\text { Compartilhar e criar } \\
\text { conhecimento tácito } \\
\text { através de experiência } \\
\text { direta. }\end{array}$ & $\begin{array}{l}\text { Indivíduo para } \\
\text { indivíduo }\end{array}$ & $\begin{array}{l}\text { Diálogos frequentes, brainstorming, trabalho do } \\
\text { tipo "mestre-aprendiz", observação e imitação, } \\
\text { compartilhamento de experiências. }\end{array}$ \\
\hline Externalização & $\begin{array}{c}\text { Articular conhecimento } \\
\text { tácito através do diálogo e } \\
\text { da reflexão. }\end{array}$ & $\begin{array}{l}\text { Indivíduo para } \\
\text { grupo }\end{array}$ & $\begin{array}{l}\text { Relatos orais ou visuais via metáforas, analogias, } \\
\text { modelos, textos, imagens, figuras, regras. }\end{array}$ \\
\hline Combinação & $\begin{array}{c}\text { Sistematizar e aplicar o } \\
\text { conhecimento explícito e a } \\
\text { informação. }\end{array}$ & $\begin{array}{l}\text { Grupo para } \\
\text { organização }\end{array}$ & $\begin{array}{l}\text { Agrupamento e processamento do conhecimento } \\
\text { explícito. }\end{array}$ \\
\hline Internalização & $\begin{array}{c}\text { Aprender e adquirir novo } \\
\text { conhecimento tácito na } \\
\text { prática. }\end{array}$ & $\begin{array}{l}\text { Organização para } \\
\text { indivíduo }\end{array}$ & $\begin{array}{l}\text { Leitura e estudo, individual, de conhecimentos } \\
\text { explícitos registrados em diferentes tipos de } \\
\text { documentos (textos, imagens, etc). }\end{array}$ \\
\hline
\end{tabular}

Fonte: adaptado de Nonaka e Takeuchi (1995)

O modelo SECI de criação do conhecimento foi proposto por Nonaka e Takeuchi (1995) abrangendo os quatro modos de conversão apresentados, como mostra a Figura 1. Convém observar que a sigla SECI é uma codificação mnemônica das primeiras letras dos modos de conversão do conhecimento (Socialização, Externalização, Combinação e Internalização). 


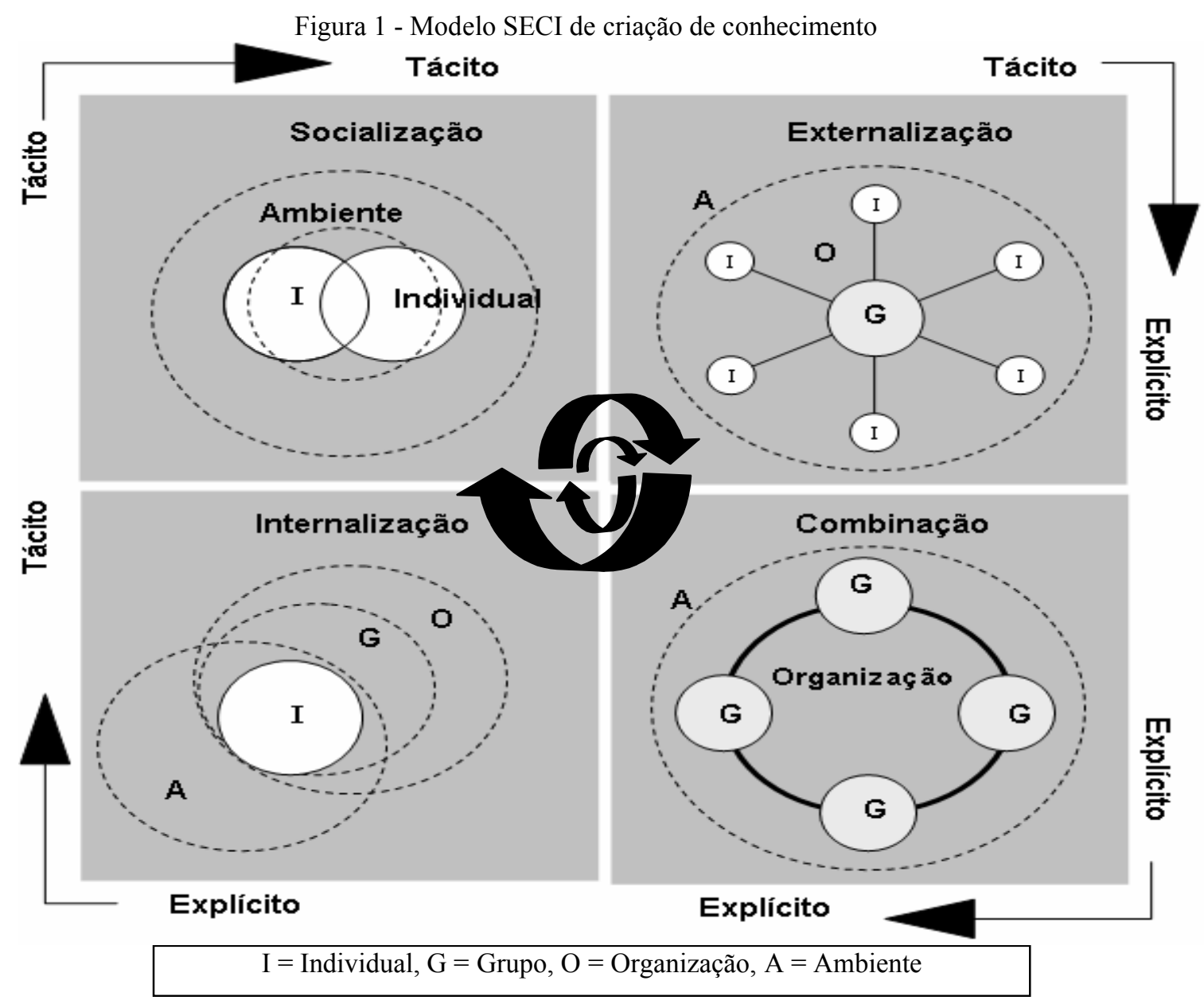

Fonte: adaptado de Nonaka e Takeuchi (1995); Nonaka e Toyama (2003)

Para a transferência do conhecimento tácito, são necessárias fortes ligações entre pessoas em espaços coletivos, tornando-se prioritária a relação "face a face". Já a transferência do conhecimento explícito pode ocorrer sem esta relação entre pessoas, podendo ser completada totalmente pelo uso, por exemplo, de meios da TI como uma intranet (CLIFFE, 1998).

\subsection{Facilitadores da Gestão do Conhecimento}

À medida que as empresas começam a gerenciar os conhecimentos organizacionais, elas precisam identificar os fatores que influenciarão o desenvolvimento consistente e sistemático de conhecimento, fatores estes conhecidos como facilitadores ou viabilizadores (enablers) da gestão de conhecimento (ICHIJO et al., 1998). Os facilitadores da GC se constituem nos mecanismos pelos quais a organização estimula a criação, o compartilhamento e a proteção do seu conhecimento (YEH et al., 2006) e define a infra-estrutura necessárias para melhorar a eficiência da gestão do conhecimento (SARVARY, 1999).

A partir de uma análise dos facilitadores identificados na literatura, Yeh et al. (2006) propõem quatro categorias-chave de facilitadores da gestão do conhecimento, a saber: estratégia e 
liderança; cultura corporativa; pessoas; e tecnologia da informação. Cada uma dessas categorias é discutida a seguir:

- Estratégia e liderança: é necessário que a empresa possua uma estratégia e que os membros do grupo tenham disposição para planejar e contribuir para a sua definição. Storey e Barnett (2000) comentam que a alta cúpula da firma deve fornecer suporte e incentivos à gestão conhecimento na empresa de forma explícita e prática. Ainda, é importante que a alta cúpula da organização, em especial o principal executivo (CEO), possua uma visão clara e metas audazes para criar uma atmosfera de participação ativa entre os que fazem a organização (ANDERSON; APQC, 1996);

- Cultura corporativa: é uma combinação de valores, crenças-chave, modelo de comportamento e emblemas. Representa o sistema de valores da companhia que se torna na norma de comportamento dos empregados. Cada cultura organizacional é independente e única. A cultura organizacional não somente define o valor do conhecimento e explica a vantagem que o conhecimento cria para a organização (LONG, 1997), mas também influencia os esforços que os empregados estão dispostos a compartilhar e colocar na companhia. Portanto, a capacidade de construir uma cultura em que haja fácil acesso ao conhecimento é necessária para a gestão de conhecimento (YEH et al., 2006);

- Pessoas: como o conhecimento é mantido no indivíduo, o ponto mais importante para a gestão do conhecimento é a forma de fazer com que o conhecimento embutido num indivíduo seja transferido para outros membros da organização, a fim de que eles possam compartilhá-lo, utilizá-lo e então convertê-lo em conhecimento da organização (NONAKA; TAKEUCHI, 1995). Eisenhardt e Santos (2002) consideram que os programas de incentivo desempenham um importante papel para a gestão de conhecimento no ambiente empresarial;

- Tecnologia da Informação: este viabilizador se refere aos elementos fundamentais da tecnologia da informação (TI) que suportam e coordenam a gestão de conhecimento, tais como: gerenciadores de bases de dados, plataformas de conhecimento, sistema de gestão de avaliação de desempenho, entre outros (BECKMAN, 1999). A tecnologia da informação pode viabilizar a pesquisa rápida, acesso e recuperação de informações, além de poder suportar a colaboração e comunicação entre os membros da organização. Zack (1999) considera que a tecnologia da informação pode desempenhar quatro papéis distintos na gestão de conhecimento, a saber: obtenção de conhecimento; definição, armazenamento, categorização, indexação e relacionamento entre os itens digitais relacionados a conhecimento; pesquisa e identificação de conteúdo relacionado; e flexibilização na expressão do conteúdo com base no histórico de utilização desse conteúdo. O uso de múltiplas tecnologias de informação pode reduzir o custo de uso da informação, aumentar a velocidade do fluxo de conhecimento (DEMAREST, 1997; DAVENPORT et al., 1998) e também 
auxiliar na criação, integração e transferência de conhecimento (ALAVI; LEIDNER, 1999).

Convém ressaltar que o emprego de TI na firma deve ser condicionado às definições e escolhas da estrutura organizacional, e não o contrário, cabendo a esses sistemas o papel de facilitadores na existência dos espaços organizacionais voltados ao processamento dos aspectos cognitivos (SALERNO, 1998), contribuindo com o tratamento e transmissão do conhecimento, em especial o explícito (MCDERMOTT, 1999). Silva (2004) pontua que a TI é fundamental para a combinação (agrupamento) dos conhecimentos explícitos, mas não contribui significativamente com o formato tácito do conhecimento. Além disso, a TI pode facilitar a externalização (auxilia no registro do conhecimento) e a internalização (agiliza o acesso ao conhecimento explícito). Desta forma, no contexto de empresas de serviços empresariais intensivos em conhecimento, o uso de tecnologia e sistemas de informação pode servir como uma arma competitiva tanto em relação aos produtos oferecidos, como também em relação ao processo de criação de novos produtos (ANDREU; CIBORRA, 1996).

A partir de pesquisas realizadas em duas grandes companhias asiáticas (ASE e VIA), Yeh et al. (2006) identificam e propõem algumas práticas e ações relacionadas aos facilitadores da gestão do conhecimento, como mostra o Quadro 3:

Quadro 3 - Facilitadores / viabilizadores da Gestão do Conhecimento e algumas práticas

\begin{tabular}{|c|c|c|c|}
\hline $\begin{array}{l}\text { FACILITADOR } \\
\text { DA GC } \\
\end{array}$ & PRÁTICAS/AÇÕES - ASE & PRÁTICAS/AÇÕES - VIA & $\begin{array}{c}\text { PRÁTICAS/AÇÕES } \\
\text { GERAIS PROPOSTAS }\end{array}$ \\
\hline $\begin{array}{l}\text { Estratégia e } \\
\text { Liderança }\end{array}$ & $\begin{array}{l}\text { - Busca de suporte dos gerentes } \\
\text { seniores e compreensão comum } \\
\text { do que é gestão de conhecimento; } \\
\text { - Avaliação contínua da estratégia } \\
\text { e nível de esforço da gestão de } \\
\text { conhecimento, e da ação } \\
\text { correspondente. }\end{array}$ & $\begin{array}{l}\text { - A presidência enfatiza a gestão de } \\
\text { conhecimento publicamente em } \\
\text { diversas ocasiões; } \\
\text { - A alta gerência concorda com a } \\
\text { importância da gestão de } \\
\text { conhecimento; } \\
\text { - Uso de indicadores específicos por } \\
\text { departamento. }\end{array}$ & 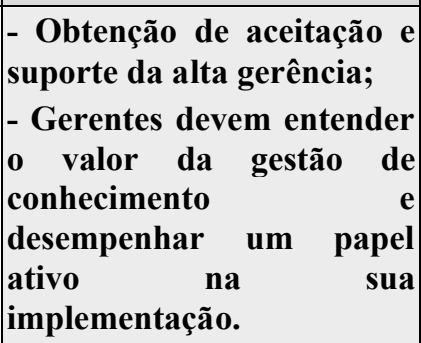 \\
\hline $\begin{array}{c}\text { Cultura } \\
\text { corporativa }\end{array}$ & $\begin{array}{l}\text { - Cada empregado deve produzir } \\
1 \text { ou } 2 \text { materiais de treinamento } \\
\text { nos seis meses iniciais no } \\
\text { emprego, revisado por um expert, } \\
\text { para estimular a cultura } \\
\text { compartilhamento }\end{array}$ & $\begin{array}{l}\text { - Comunicação da importância da } \\
\text { GC em eventos formais de } \\
\text { treinamento ou reuniões gerenciais; } \\
\text { - Implementação da abordagem de } \\
\text { GC em nível departamental. }\end{array}$ & $\begin{array}{l}\text { - Construir um ambiente } \\
\text { de compartilhamento entre } \\
\text { os empregados, com } \\
\text { suporte da tecnologia da } \\
\text { informação. }\end{array}$ \\
\hline Pessoas & $\begin{array}{l}\text { - Treinamento no nível } \\
\text { corporativo; } \\
\text { - Treinamento departamental; } \\
\text { - Auto-treinamento; } \\
\text { - Propostas de inovação são } \\
\text { avaliadas por experts. }\end{array}$ & 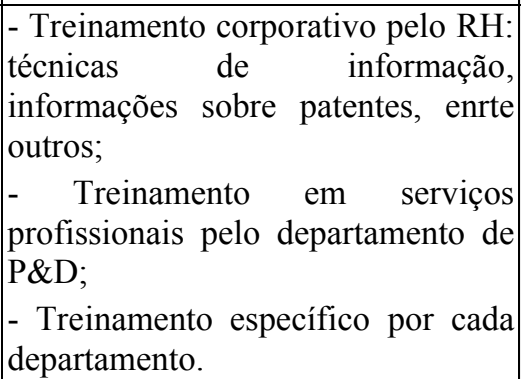 & $\begin{array}{l}\quad \text { Oferecimento de } \\
\text { treinamentos formais e e } \\
\text { canais de aprendizado; } \\
\text { - Utilização de sistema de } \\
\text { recompensas. }\end{array}$ \\
\hline
\end{tabular}




\begin{tabular}{|c|c|c|c|}
\hline $\begin{array}{l}\text { Tecnologia da } \\
\text { Informação }\end{array}$ & $\begin{array}{l}\text { - Uso de plataforma de conexão } \\
\text { do banco de dados e } \\
\text { disponibilização de mecanismo } \\
\text { de busca similar ao Google } \\
\text { apenas para funcionários internos } \\
\text { (proteção da informação). }\end{array}$ & $\begin{array}{l}\text { - Divisão de e-Business desenvolve } \\
\text { a solução corporativa de gestão de } \\
\text { conhecimento. }\end{array}$ & 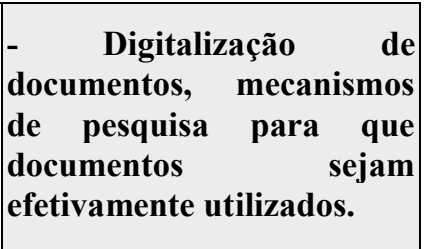 \\
\hline $\begin{array}{c}\text { Responsável } \\
\text { específico pela } \\
\text { GC }\end{array}$ & - Centro de GC. & - Sem área específica para GC. & $\begin{array}{l}\text { - Estabelecimento de uma } \\
\text { unidade dedicada à GC. }\end{array}$ \\
\hline
\end{tabular}

Como indicativo da relevância das proposições de Yeh et al.(2006), outras pesquisas foram realizados tomando como base as quatro categorias de facilitadores propostas pelos autores. Como exemplo, pode ser citada a pesquisa realizada por Lee et al. (2008) que, a partir de um estudo empírico realizado em 151 empresas, 77 das quais tidas como "de serviços", concluem que no contexto de micro e pequenas a utilização das categorias de viabilizadores da GC de Yeh et al.(2006), ressalvando a TI, aliada ao estabelecimento de um departamento ou unidade dedicada especificamente à GC, impactam positivamente no desempenho de elementos não-financeiros da organização, tais como os relacionados com as perspectivas: (i) de aprendizado e crescimento (ex: satisfação de funcionários, compartilhamento de conhecimento, entre outros); (ii) de processos internos (ex: qualidade dos serviços, velocidade de resposta às necessidades dos clientes, entre outros); e (iii) de clientes (ex: satisfação e fidelidades de clientes, número de reclamações, entre outros).

\section{Metodologia da Pesquisa}

A escolha de um método depende dos pressupostos que orientam o pesquisador ao defrontar-se com o problema de pesquisa. A pesquisa feita neste trabalho emprega o método hipotético-dedutivo (DANE, 1990) na medida em que parte de teorias sobre o processo de criação do conhecimento e sobre os facilitadores da GC, descartando aquelas que não servem a presente pesquisa. O problema de pesquisa é abordado, principalmente, de forma qualitativa e descritiva, pois visa descrever e interpretar as características de determinado fenômeno (os relacionamentos existentes entre os facilitadores da GC com as conversões do conhecimento no PDP de uma empresara de consultoria empresarial), definindo-os e os delimitando com a ajuda de um framework de mapeamento proposto.

Em termos de método de procedimento de pesquisa, o presente trabalho emprega o estudo de caso, pois este é adequado à necessidade de se testar o framework de mapeamento dos facilitadores da GC no PDP, verificando as teorias empregadas na construção deste framework (YIN, 2005; MARCONI; LAKATOS, 2008). A metodologia segue, ainda, uma pesquisa de campo 
que, conforme Marconi e Lakatos (2008, p. 188), “consiste na observação de fatos e fenômenos tal como ocorrem espontaneamente, na coleta de dados a eles referentes e no registro de variáveis que se presumem relevantes, para analisá-los". Essa pesquisa de campo foi aplicada dentro de uma empresa de consultoria empresarial brasileira. Foram realizadas entrevistas com pessoas-chave e coletados dados in loco no PDP da empresa (então chamado de setor de Pesquisa e Desenvolvimento - P\&D). Além das entrevistas, foram coletadas fontes de evidência na pesquisa de campo nos termos apresentados por Yin (2005), como mostra o Quadro 4:

Quadro 4 - Fontes de evidências coletadas na pesquisa de campo

\begin{tabular}{|c|c|}
\hline $\begin{array}{c}\text { FONTE DE } \\
\text { EVIDÊNCIAS }\end{array}$ & PRINCIPAIS ENTIDADES TRABALHADAS E MATERIAIS COLETADOS \\
\hline Documentação & $\begin{array}{l}\text { - Programa formal de desenvolvimento de serviços da empresa; } \\
\text { - Programa formal de avaliação de desempenho dos funcionários e gestores; } \\
\text { - Manuais instrutivos de execução dos serviços. }\end{array}$ \\
\hline $\begin{array}{l}\text { Registros em } \\
\text { arquivos }\end{array}$ & $\begin{array}{l}\text { - Atas das reuniões de todos os grupos de desenvolvimento de serviços (denominados de "grupos de } \\
\text { P\&D"); } \\
\text { - Memorial dos serviços prestados contendo pontos fortes, dificuldades e peculiaridades. }\end{array}$ \\
\hline $\begin{array}{l}\text { Entrevistas } \\
\quad \text { (semi- } \\
\text { estruturadas) }\end{array}$ & $\begin{array}{l}\text { - Diretor-Presidente; } \\
\text { - Diretor de P\&D; } \\
\text { - "Tutores" de cada grupo de P\&D (total de } 4 \text { pessoas); } \\
\text { - } 2 \text { membros de cada grupo de P\&D (total de } 8 \text { pessoas). }\end{array}$ \\
\hline $\begin{array}{c}\text { Observações } \\
\text { diretas }\end{array}$ & - Observação de 1 reunião de discussão de cada grupo de P\&D (total de 4 observações diretas). \\
\hline $\begin{array}{l}\text { Observação } \\
\text { participante }\end{array}$ & - Participação em 2 reuniões dos diretores da empresa \\
\hline $\begin{array}{l}\text { Artefatos } \\
\text { físicos }\end{array}$ & $\begin{array}{l}\text { - Quadro com programação das reuniões de discussão dos serviços da empresa; } \\
\text { - Banner com declaração de missão, visão e valores; } \\
\text { - Biblioteca da empresa; } \\
\text { - Canal de interlocução eletrônico acessível a todos os funcionários e gestores da empresa. }\end{array}$ \\
\hline
\end{tabular}

Fonte: Autoria própria (2009)

\section{Framework Proposto}

O que sustenta a proposição deste estudo é que a análise das conversões do modelo SECI, em cada uma das dimensões, pode ser usada para investigar como os conhecimentos são criados ou trabalhados em todo o processo de desenvolvimento de produtos de uma empresa de serviços empresariais intensivos em conhecimento de uma forma integrada com os facilitadores da GC. Esta proposta pode, então, resultar em um efetivo framework de mapeamento da GC no processo de desenvolvimento de produtos. A proposição de um framework de mapeamento dos viabilizadores da GC no PDP parte do pressuposto de que já existem iniciativas de conversões do conhecimento no processo de PDP na empresa. O foco está em considerar estas iniciativas e mapeá-las, entendendo como são realizadas e detectando lacunas existentes. A Figura 2 expõe a estrutura do framework proposto: 
Figura 2 - Framework de mapeamento dos facilitadores / viabilizadores da GC no PDP de empresas prestadoras de serviços intensivos em conhecimento

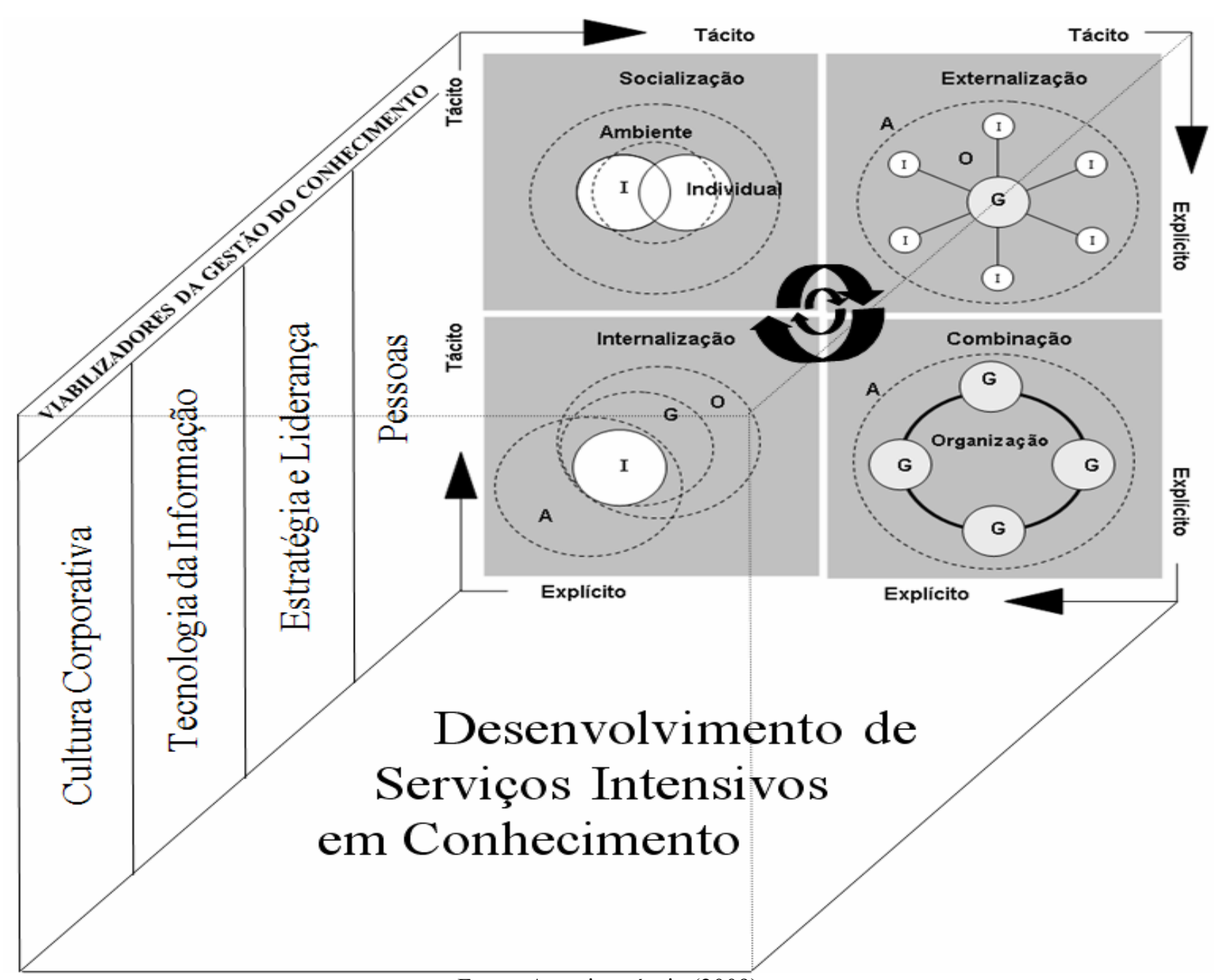

Fonte: Autoria própria (2009)

Tomando como base as contribuições aportadas nas obras de Nonaka e Takeuchi (1995) e de Yeh et al. (2006), um conjunto de ações e práticas que podem servir de base para a operacionalização do framework de mapeamento proposto é apresentado no Quadro 5:

Quadro 5 - Ações e práticas relacionadas com a operacionalização do framework de mapeamento proposto

\begin{tabular}{|c|c|c|c|c|}
\hline \multicolumn{5}{|c|}{ AÇÕES E PRÁTICAS } \\
\hline \multirow{2}{*}{$\begin{array}{l}\text { FACILITADOR } \\
\text { GC }\end{array}$} & \multicolumn{4}{|c|}{ CONVERSÃO DO CONHECIMENTO } \\
\hline & Socialização & Externalização & Combinação & Internalização \\
\hline $\begin{array}{l}\text { Estratégia e } \\
\text { Liderança }\end{array}$ & $\begin{array}{l}\text { - Alta direção apóia } \\
\text { iniciativas de } \\
\text { trabalho em grupo; } \\
\text { - Líderes promovem } \\
\text { encontros para troca } \\
\text { de experiências. }\end{array}$ & $\begin{array}{l}\text { - Alta direção apóia a } \\
\text { criação de mecanismos } \\
\text { para que os } \\
\text { funcionários registrem: } \\
\text { problemas, causas e } \\
\text { soluções; idéias; } \\
\text { descobertas; e novas } \\
\text { práticas. }\end{array}$ & \begin{tabular}{|lrr}
$\quad$ Alta & direção \\
incentiva & & a \\
descoberta/criação & de \\
mecanismos & & de \\
inferência & e & de \\
mineração & & de \\
informações. & &
\end{tabular} & $\begin{array}{l}\text { - Alta direção cria } \\
\text { facilidades de acesso à } \\
\text { informação a todos as } \\
\text { pessoas da firma; } \\
\text { - Líderes motivam } \\
\text { subordinados a buscar } \\
\text { soluções já codificadas. }\end{array}$ \\
\hline $\begin{array}{c}\text { Cultura } \\
\text { corporativa }\end{array}$ & $\begin{array}{lr}\text { - Encontros e } & \text { troca } \\
\text { de idéias } & \text { são }\end{array}$ & \begin{tabular}{|lr|}
\multicolumn{2}{|c}{ Registrar descobertas } \\
e $\quad$ soluções & de \\
problemas & é
\end{tabular} & \begin{tabular}{|lr} 
- Funcionários & são \\
incentivados a criarem \\
hábitos & de:
\end{tabular} & $\begin{array}{l}\text { - São desenvolvidos } \\
\text { mecanismos para acesso } \\
\text { ao conhecimento da firma }\end{array}$ \\
\hline
\end{tabular}




\begin{tabular}{|c|c|c|c|c|}
\hline & $\begin{array}{|lr|}\text { valorizados; } & \\
\text { - Disseminação } & \text { de } \\
\text { conhecimento } & \text { é } \\
\text { incentivada } & \text { e } \\
\text { "gratificada". } & \\
\end{array}$ & $\begin{array}{l}\text { considerado como uma } \\
\text { atitude positiva e de } \\
\text { mérito. }\end{array}$ & $\begin{array}{l}\text { questionamento; } \\
\text { associação de idéias e } \\
\text { soluções; busca de } \\
\text { correlações; e descarte } \\
\text { de conhecimento } \\
\text { obsoleto. }\end{array}$ & $\begin{array}{l}\text { e do ambiente; } \\
\text { - Funcionários são } \\
\text { incentivados a conhecer o } \\
\text { "acervo" de } \\
\text { conhecimentos da firma e } \\
\text { do ambiente e a utilizá-los } \\
\text { de forma crítica. }\end{array}$ \\
\hline Pessoas & 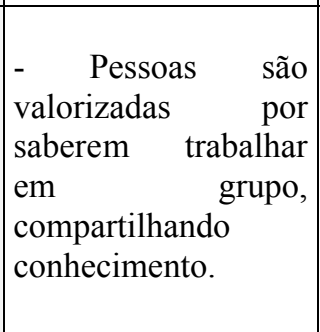 & $\begin{array}{l}\text { - Pessoas são } \\
\text { motivadas a dispor seu } \\
\text { conhecimento e ter o } \\
\text { sentimento de que isto } \\
\text { será benéfico para si e } \\
\text { para a firma. }\end{array}$ & $\begin{array}{l}\text { - Pessoas são } \\
\text { motivadas a questionar } \\
\text { conhecimentos } \\
\text { existentes e a buscar } \\
\text { correlação com outras } \\
\text { informações } \\
\text { disponíveis na firma e } \\
\text { no ambiente. }\end{array}$ & $\begin{array}{l}\text { - Pessoas têm consciência } \\
\text { de que a firma para a qual } \\
\text { trabalha e ambiente que a } \\
\text { firma está inserida tem um } \\
\text { acervo de informações que } \\
\text { pode enriquecer e } \\
\text { aumentar seu } \\
\text { conhecimento e formação. }\end{array}$ \\
\hline $\begin{array}{l}\text { Tecnologia da } \\
\text { Informação }\end{array}$ & $\begin{array}{l}\text { - São desenvolvidos } \\
\text { mecanismos para } \\
\text { que o conhecimento } \\
\text { esteja disponível em } \\
\text { qualquer local e } \\
\text { momento } \\
\text { (computação } \\
\text { pervasiva) }\end{array}$ & $\begin{array}{l}\text { - São disponibilizados } \\
\text { mecanismos r para } \\
\text { registrar de forma } \\
\text { consciente } \\
\text { inconsciente todas as } \\
\text { novas informações do } \\
\text { dia-a-dia. }\end{array}$ & \begin{tabular}{|lr} 
- São proporcionados \\
mecanismos \\
facilitadores & para \\
associar e & inferir \\
conhecimento & de \\
informações & já \\
registradas. &
\end{tabular} & $\begin{array}{l}\text { - São fornecidas } \\
\text { facilidades para que as } \\
\text { pessoas possam ter acesso } \\
\text { (com qualidade, de forma } \\
\text { intuitiva e facilitada.) às } \\
\text { informações armazenadas. }\end{array}$ \\
\hline $\begin{array}{c}\text { Responsável } \\
\text { Específico pela } \\
\text { GC }\end{array}$ & & & o ou umi gi upo/consetino & específico para a GC \\
\hline
\end{tabular}

Fonte: Autoria própria (2009)

\section{Aplicação do Framework Proposto}

Esta seção apresenta à aplicação do framework proposto em uma empresa de pequeno porte brasileira prestadora de serviços de consultoria empresarial A empresa possui quatro equipes responsáveis pelo PDP denominadas "Grupos de Pesquisa e Desenvolvimento" que atuam nas seguintes áreas de conhecimento: gestão da qualidade; planejamento, programação e controle da produção; planejamento de manutenção; e gestão de custos. A partir das fontes de evidência coletadas apresentadas no quadro 4, foram mapeadas no processo de desenvolvimento de produtos da empresa, as práticas e ações relacionadas com cada processo de conversão do conhecimento do modelo SECI e com cada viabilizador da GC. Vale destacar que foi mapeada também a existência ou não de um responsável direto pela GC da empresa. O Quadro 6 apresenta os resultados obtidos:

Quadro 6: Ações e práticas relacionadas com o desenvolvimento de serviços da empresa em estudo

\begin{tabular}{|c|c|c|c|c|}
\hline \multicolumn{5}{|c|}{$\begin{array}{l}\text { AÇÕES E PRÁTICAS RELACIONADAS COM O DESENVOLVIMENTO DE PRODUTOS DA EMPRESA } \\
\text { EM ESTUDO }\end{array}$} \\
\hline \multirow{2}{*}{$\begin{array}{l}\text { VIABILIZADOR } \\
\text { DA GC }\end{array}$} & \multicolumn{4}{|c|}{ CONVERSÕES DO CONHECIMENTO } \\
\hline & Socialização & Externalização & Combinação & Internalização \\
\hline $\begin{array}{l}\text { Estratégia e } \\
\text { Liderança }\end{array}$ & $\begin{array}{l}- \text { - O Diretor- presidente } \\
\text { enfatiza a importância } \\
\text { da gestão r de } \\
\text { conhecimento } \\
\text { publicamente } \\
\text { diversas ocasiões; }\end{array}$ & $\begin{array}{lrr}\text { - As atividades } & \text { de } \\
\text { desenvolvimento } & \text { de } \\
\text { serviços } & \text { são } \\
\text { realizadas em } & 4 \\
\text { grupos de P\&D; } & \\
\text { - Os tutores } & \text { dos }\end{array}$ & $\begin{array}{lr}\text { - Há a participação de } \\
\text { Diretores } & \mathrm{e}, \\
\text { principalmente, } & \mathrm{dos} \\
\text { tutores dos grupos } & \mathrm{de} \\
\mathrm{P} \& \mathrm{D} \text { em processos } & \mathrm{de} \\
\text { benchmarking } & \mathrm{e}\end{array}$ & $\begin{array}{l}\text { - Há parcerias com } \\
\text { instituições públicas } \\
\text { centros de pesquisas a } \\
\text { partir dos quais os } \\
\text { funcionários da empresa } \\
\text { podem absorver e trocar }\end{array}$ \\
\hline
\end{tabular}




\begin{tabular}{|c|c|c|c|c|}
\hline & 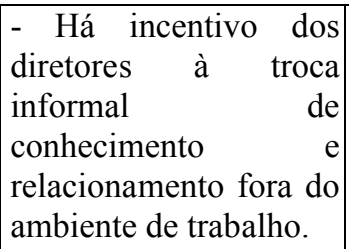 & $\begin{array}{ll}\text { grupos são orientados } \\
\text { a provocarem } & 0 \\
\text { debate buscando a } & \\
\text { síntese das idéias. } & \end{array}$ & $\begin{array}{l}\text { prospecção de novas } \\
\text { técnicas e tendências. }\end{array}$ & $\begin{array}{l}\text { conhecimentos } \\
\text { experiências. }\end{array}$ \\
\hline $\begin{array}{c}\text { Cultura } \\
\text { corporativa }\end{array}$ & $\begin{array}{lcr}\text { - } & \text { E realizada } & a \\
\text { comunicação } & \text { da } \\
\text { importância da gestão } \\
\text { de conhecimento em } \\
\text { eventos formais } & \text { ou } \\
\text { reuniões gerenciais. }\end{array}$ & $\begin{array}{l}\text { - Os membros dos } \\
\text { grupos de P\&D são } \\
\text { provocados a terem } \\
\text { uma postura crítica } \\
\text { na busca de uma } \\
\text { síntese de idéias } \\
\text { contrastantes. }\end{array}$ & $\begin{array}{l}\text { - São realizadas } \\
\text { sistematicamente } \\
\text { reuniões entre os } \\
\text { tutores dos grupos de } \\
\text { P\&D e os diretores da } \\
\text { empresa para discutir } \\
\text { projetos. }\end{array}$ & $\begin{array}{l}\text { - Cada novo entrante da } \\
\text { empresa passa por um } \\
\text { programa de job rotation } \\
\text { pelos grupos de P\&D. }\end{array}$ \\
\hline Pessoas & $\begin{array}{lr}\text { - São realizados } \\
\text { treinamentos } & \text { sobre } \\
\text { técnicas } & \text { de } \\
\text { comunicação } & \\
\text { ministrados pelo } & \mathrm{RH} \mathrm{da} \\
\text { empresa. }\end{array}$ & $\begin{array}{l}\text { - Há pluralidade de } \\
\text { conhecimentos e } \\
\text { pessoas nos Grupos } \\
\text { de P\&D; } \\
\text { - Há um sistema } \\
\text { formal de avaliação } \\
\text { de desempenho e } \\
\text { remuneração pelas } \\
\text { contribuições dadas a } \\
\text { cada grupo de P\&D. }\end{array}$ & $\begin{array}{l}\text { - Metodologias } \\
\text { universais são definidas } \\
\text { para confecção dos } \\
\text { manuais básicos de } \\
\text { serviços de consultoria; } \\
\text { - Todos os projetos e } \\
\text { idéias discutidas e } \\
\text { sintetizadas nos grupos } \\
\text { de P\&D são repassados } \\
\text { a todos os integrantes } \\
\text { da empresa. }\end{array}$ & $\begin{array}{lrr} & \text { São } & \text { realizados } \\
\text { treinamentos } & \text { corporativos } \\
\text { externos; } & \\
- & \text { São } & \text { ministrados } \\
\text { treinamentos } & \text { em } & \text { serviços } \\
\text { profissionais } & & \text { de } \\
\text { consultoria } & & \text { pelo } \\
\text { departamento } & \text { de } & \text { P\&D } \\
\text { (visão geral); } & & \\
\text { - São } & \text { ministrados } \\
\text { treinamentos } & \text { específicos } \\
\text { em cada departamento e } \\
\text { em cada grupo de P\&D; } \\
\text { - Há disponibilização de } \\
\text { biblioteca para } \\
\text { treinamento/estudo; } \\
\text { - Há incentivo financeiro } \\
\text { para participação } \\
\text { eventos e feiras. }\end{array}$ \\
\hline $\begin{array}{l}\text { Tecnologia da } \\
\text { Informação }\end{array}$ & & $\begin{array}{l}- \\
\text { disponibilizadas } \\
\text { ferramentas para a } \\
\text { realização } \\
\text { reuniões virtuais dos } \\
\text { grupos de P\&D; } \\
\text { - Espaços para } \\
\text { discussão na web são } \\
\text { utilizados. }\end{array}$ & $\begin{array}{l}\text { - Há a possibilidade de } \\
\text { discussão dos projetos } \\
\text { de cada grupo pelos } \\
\text { diretores da empresa } \\
\text { via internet. }\end{array}$ & 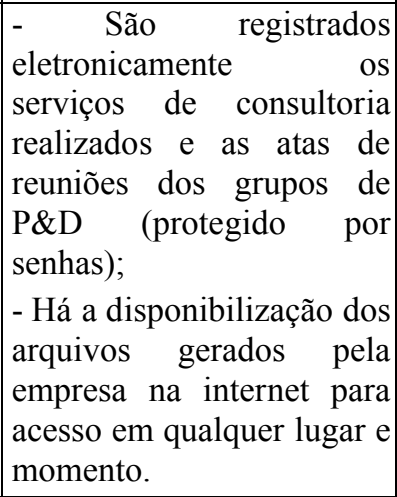 \\
\hline $\begin{array}{c}\text { Responsável } \\
\text { Específico pela } \\
\text { GC } \\
\end{array}$ & \multicolumn{4}{|c|}{ Diretoria de P\&D } \\
\hline
\end{tabular}

Fonte: Autoria própria (2009)

\subsection{Análise dos Resultados}

A Socialização e a Externalização são os processos de conversão do conhecimento com maior ocorrência no processo de DP. Estes resultados confirmam a percepção de que existe, na empresa estudada, um ambiente favorável à Socialização, resultado de ações empreendidas nos últimos anos para uma melhor comunicação e trabalho "face à face" entre as pessoas envolvidas 
com o DP (como, por exemplo, o incentivo e a preparação para o trabalho em grupo, existência de avaliação de desempenho pautada em resultados coletivos, etc.). No entanto, notou-se certo grau de dificuldade em se registrar (na forma de atas, por exemplo) as discussões realizadas nos grupo de P\&D.

A Combinação possui uma posição intermediária de ocorrência no processo de DP da empresa, principalmente, devido a uma deficiência na discussão da evolução de cada grupo em um nível mais abrangente e estratégico. Este processo de conversão ocorre com mais intensidade na dimensão (viabilizador/enabler) Pessoas. A Internalização é a conversão do conhecimento com menor ocorrência no processo de DP. Apesar de fazer o uso de alguns recursos e meios de comunicação eletrônicos, a falta de uma moderna estrutura de TI foi constatada como a principal causa desta deficiência identificada no DP da empresa. Outros fatores também possuem relevância para esta deficiência, tais como a declarada "falta de tempo" para a leitura (estudo) dos manuais e documentos gerados e a preferência pela busca de conhecimentos via contatos com outras pessoas.

Ainda analisando alguns aspectos relacionados às conversões do conhecimento no estudo de caso, percebe-se que a transmissão de experiências e práticas do processo de DP se dá quase totalmente pela via tácita e, portanto, é fortemente dependente da Socialização, com vantagens (facilidade e rapidez) e desvantagens (monopólio individual do conhecimento e perda da memória corporativa). Atuar nas causas deste problema significa criar condições, especialmente preparo e tempo, para que as pessoas realizem mais leituras/estudos (Internalização) e, principalmente, estejam preparadas e motivadas para registrar (Externalização) com mais regularidade as experiências, práticas e discussões realizadas.

De posse do "mapa" gerado a partir da aplicação do framework proposto, tanto os gestores dos grupos de P\&D, como também os diretores da empresa, puderam diagnosticar a situação dos processos de criação e gestão do conhecimento na empresa, em especial no desenvolvimento de serviços.

\section{Considerações Finais}

Este trabalho apresentou um framework útil para o mapeamento dos facilitadores/viabilizadores da gestão do conhecimento em relação a cada processo de conversão do modelo SECI de criação de conhecimento. Este framework foi aplicado no processo de desenvolvimento de produtos de uma empresa prestadora de serviços intensivos em conhecimento (KIBS - Knowledge Intensive Business Services), no caso, uma empresa de consultoria empresarial. Desta forma, conseguiu-se atingir o objetivo do estudo. 
No caso da organização estudada, o framework de mapeamento possibilitou que os gestores da empresa verificasse em que instâncias o processo de criação e gestão do conhecimento precisavam ser melhorados ou estavam fortalecidos. Desta forma, espera-se que ações e decisões futuras no tocante ao desenvolvimento dos serviços da empresa possam ser mais bem direcionadas. Vale ressaltar que o framework de mapeamento deve ser reaplicado de tempos em tempos de forma a manter atualizada a situação da GC da empresa.

Dentre as limitações do trabalho, destaca-se a restrição de foco que impediu um estudo mais detalhado de cada viabilizador em cada processo de conversão, já que a prioridade escolhida foi o mapeamento da GC apenas no processo de DP. No entanto, trabalhos futuros poderão ter no atual estudo um ponto de partida para aprofundamentos em dimensões específicas. Para tal, outros caminhos podem ser explorados, tal como o da utilização de uma análise mais profunda no DP de empresas do que a proporcionada por meio do estudo de caso. Além disso, ao se decidir pelo uso do estudo de caso, os resultados foram tornam-se impossibilitados de serem generalizados para uma população ou universo (generalização estatística).

Vale ressaltar que o framework de mapeamento da GC no processo de DP verifica-se longe de se esgotar e com inúmeras possibilidades de novas contribuições. Finalmente, idealiza-se que este estudo contribua como um referencial para outras pesquisas.

\begin{abstract}
In modern economies, the participation of the service sector in employment and value creation is increasing. Part of this sector, called KIBS (Knowledge-Intensive Business Services), relates to companies in which knowledge is the main source of resources and competitive advantage. In this context, the aim is to propose a framework for mapping the knowledge management enablers to be applied in the product development of a firm which provides knowledgeintensive services such as business consultancy. From a case study, the proposed framework is applied in a Brazilian firm that provides business consulting services. From the findings, it is concluded that the proposed framework is useful to help managers to diagnose the instances in which the process of knowledge creation and management need improvement or are strengthened on the development of knowledge-intensive services.
\end{abstract}

Key-words: magazine, articles, formatting.

\title{
Referências
}

ALAVI, M.; LEIDNER, D. E. Knowledge management system: issues, challenges, and benefits. Communications of the AIS, v. 1, n. 7, p. 1-37, 1999.

ANDERSON, A.; APQC. The Knowledge Management Assessment Tool: External Benchmarking Version. Arthur Anderson/APQC, Chicago, 1996.

ANDREU, R.; CIBORRA, C. Organisational learning and core capabilities development: the role of IT. Journal of Strategic Information Systems, v. 5, p. 111-127, 1996.

cross ${ }^{\text {ref }}$

ANTONELLI, C. Localizad technological change, new information technology and the knowledge and the knowledgebased economy: the European evidence. Journal of Evolutionary Economics, v. 8, p. 177-198, 1998. 
BECKMAN, T. J. The current state of knowledge management. In LIEBOWITZ, J. (Org.) Knowledge Management Handbook. Boca Raton: CRC Press, 1999.

CLIFFE, S. Knowledge management the well-connected business. Harvard Business Review, v. 76, n. 4, p. 1721,1998 .

DANE, F. C. Research Methods. Belmont: Brooks/Cole, 1990.

DAVENPORT, T.; DE LONG, D.W.; BEERS, M.C. Successful knowledge management projects. Sloan Management Review, v. 39, n. 2, p. 43-57, 1998.

DAVENPORT, T.; PRUSAK, L. Working Knowledge: How Organizations manage what they know. Cambridge, MA. Harvard Business School Press, 2000.

DEMAREST, M. Understanding knowledge management. Long Range Planning, v. 30, n. 3, p. 374-384, 1997. cross ${ }^{\text {ref }}$

DRUCKER, P. A Sociedade Pós Capitalista. São Paulo: Ed. Pioneira, 1993.

DUHAN, S.; LEVY, M.; POWELL, P. Information systems strategies in knowledge-based SMEs: the role of core competencies. European Journal of Information System, v. 10, n. 1, p. 25-41, 2001.

cross ${ }^{\text {ref }}$

EISENHARDT, K. M.; SANTOS, F. M. Knowledge-based view: a new theory of strategy. Handbook of Strategy and Management. London: Sage, 2002.

HAUKNES, J. Knowledge intensive services - what their role? In: OECD Business and Industry Policy Forum on Realising the Potential of the Service Economy: Facilitating Growth, Innovation and Competition, Paris, 2009.

HAYES, R. H.; PISANO, G. P. Beyond world-class: the new manufacturing strategy. Harvard Business Review, v. 72, n. 1, p. 77-86, Jan-Feb, 1994.

ICHIJO, K.; KROUGH, G.; NONAKA, I. Knowledge enablers. In: KROGH, G; ROOS, J.; KLEINE. D. (Orgs.) Knowing in Firms. London: Sage Publications, 1998.

JESUS, H. A. A contribuição dos serviços empresariais intensivos em conhecimento (KIBS) para o desenvolvimento regional. Revista de Desenvolvimento Econômico, ano VII, nº 12, 2005.

KUBOTA, L. C. As KIBS e a inovação tecnológica das firmas de serviços. In: ENCONTRO NACIONAL DA ANPEC, Salvador. Anais... Salvador: ANPEC, 2006.

LEE, C. -L.; HO, C. -T.; CHIU, Y. -L. The impact of knowledge management enablers on non-financial performance in small and medium enterprises. International Journal of Technology Management, v. 43, n. 1-3, p. 266-283, 2008.

cross ${ }^{\text {ref }}$

LONG, D. D. Building the knowledge-based organizations: how culture drives knowledge behaviors. Working paper of the Center for Business Innovation, Ernst \& Young LLP, Cambridge, MA, 1997.

MARCONI, M. A.; LAKATOS, E. M. Fundamentos de Metodologia Científica. $6^{\text {a }}$ ed. São Paulo: Editora Atlas, 2008 .

MCDERMOTT, R. Why information technology inspired but cannot deliver knowledge management. California Management Review, v. 41, n. 4, p. 103-117, 1999.

MILES, I.; KASTRINOS, N.; FLANAGAN, K.; BILDERBEEK, R.; HERTOG, P. Knowledge-intensive business services: users, carriers and sources of innovation. Manchester: PREST, 1995.

MULLER, E. Innovation interactions between knowledge-intensive business services and small and medium sized enterprises: an analysis in terms of evolution, knowledge and territories. Heidelberg: Physica, 2001.

MULLER, E.; DOLOREUX, D. The key dimensions of knowledge-intensive business services (KIBS) analysis: a decade of evolution. Working Papers Firms and Region, Fraunhofer Institute Systems and Innovation Research, 2007.

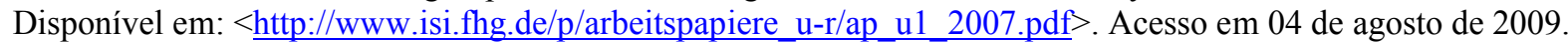


NAKANO, D. N. Gestão do conhecimento em serviços profissionais: um estudo em empresas de consultoria. 2002. 184f. Tese (Doutorado em Engenharia de Produção) - Programa de Pós-Graduação em Engenharia de Produção, Escola Politécnica da Universidade de São Paulo, São Paulo.

NONAKA, I.; TAKEUCHI, H. The Knowledge-Creating Company, How Japanese Companies Create the Dynamics of Innovation. New York: Oxford University Press, 1995.

NONAKA, I.; TOYAMA, R. The knowledge-creating theory revisited:knowledge creation as a synthesizing process. Knowledge Management Research \& Practice, v. 1, p. 2-10, 2003.

cross ref

POLANYI, M. The tacit dimension. Glouceste: Peter Smith, 1966.

QUINN, J. B.; BARUCH, J. J.; ZIEN, K. A. Innovation explosion: using intellect and software to revolutionize growth strategies. New York: Free Press, 1997.

SALERNO, M. Projeto organizacional de produção integrada, flexível e de gestão democrática: processos, grupos e espaços de comunicação-negociação. 1998. 259 f. Tese (Livre-docência) - Programa de Pós-Graduação de Engenharia de Produção, Escola Politécnica da Universidade de São Paulo, São Paulo.

SARVARY, M. Knowledge management and competition in the consulting industry. California Management Review, v. 41, p.95-107, 1999.

SILVA, S. L. Gestão do conhecimento: uma revisão crítica orientada pela abordagem da criação do conhecimento. Ciência da Informação, v. 33, n.2, p. 143-151, 2004.

crossef

SILVA, S. L.; ROZENFELD, H. Modelo de avaliação da gestão do conhecimento no processo de desenvolvimento do produto: aplicação em um estudo de caso. Produção, v. 13, n. 2, p. 6-20, 2003.

cross ${ }^{\text {ref }}$

SPENDER, J. C. Making knowledge the basis of a dynamic theory of the firm. Strategic Management Journal, v. 17, special issue in SI, p. 45-62, 1996.

STOREY, J.; BARNETT, E. Knowledge management initiatives: learning from failure. Journal of Knowledge Management, v. 4, n. 2, p. 145-156, 2000.

cross ${ }^{\text {ref }}$

THOMKE, S.; REINERTSEN, D. Agile product development: managing development flexibility in uncertain environments. California Management Review, v. 41, n. 1, p. 8-30, 1998.

YEH, Y. -J.; LAI, S. -Q; HO, C. -T. Knowledge management enablers: a case study. Industrial Management \& Data Systems, v. 106, n. 6, p. 793-810, 2006.

cross ${ }^{\text {ef }}$

YIN, R. K. Estudo de Caso: planejamento e método. 3ª ed. Porto Alegre: Bookman, 2005.

ZACK, M. H. Enveloping a knowledge strategy. California Management Review, v. 4, n. 3, p. 125- 145, 1999.

\section{Dados dos Autores:}

Nome completo: Eng ${ }^{0}$. Abraão Freires Saraiva Júnior

Filiação institucional: Escola Politécnica da Universidade de São Paulo

Departamento: Engenharia de Produção

Função ou cargo ocupado: Pesquisador do grupo de pesquisa em Economia da Produção e 


\section{Engenharia Financeira (EPEF)}

Endereço completo para correspondência (bairro, cidade, estado, país e CEP): Av. Prof. Almeida Prado, travessa 2, no 128, Cidade Universitária, CEP: 05508-070. São Paulo-SP, Brasil.

Telefones para contato: +551188294729 / +551179961170

e-mail: abraaofsjr@gmail.com

Nome completo: Engo ${ }^{\circ}$ Reinaldo Pacheco Da Costa

Filiação institucional: Escola Politécnica da Universidade de São Paulo

Departamento: Engenharia de Produção

Função ou cargo ocupado: Professor Doutor (graduação e pós-graduação)

Endereço completo para correspondência (bairro, cidade, estado, país e CEP): Av. Prof. Almeida Prado, travessa 2, no 128, Cidade Universitária, CEP: 05508-070. São Paulo-SP, Brasil.

Telefones para contato: +551130915399 ramal 408

e-mail: rpcosta@usp.br

Recebido para publicação em: 18/09/2009

Aceito para publicação em: 06/11/2009 